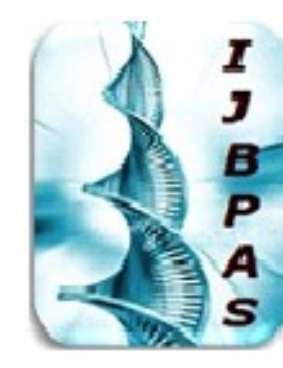

International Journal of Biology, Pharmaey and Allied Seiences (IJBPAS)

'A Bridge Betuen caboratory and QRender'

Www.ibpas.com

\title{
A REVIEW ON APPLICATIONS OF LIPASE
}

\section{MAVI H ${ }^{1}$, ANDHARE $P^{2}$, MARCHAWALA $F^{2}$, BHATTACHARYA $I^{2}$ AND UPADHYAY $\mathbf{D}^{2 *}$}

1: Student, MSc Microbiology, Parul Institute of Applied Sciences, Parul University, Post Limda, Waghodia, Gujarat, 391760

2: Assistant Professor, Parul Institute of Applied Sciences, Parul University, Post Limda, Waghodia, Gujarat, 391760

*Corresponding Author: Dr. Dhwani Upadhyay; E Mail:dhwani.updhyay82123@paruluniversity.ac.in;

Tel: +919558021474

Received 22 ${ }^{\text {nd }}$ Jan. 2021; Revised 24 ${ }^{\text {th }}$ Feb. 2021; Accepted $25^{\text {th }}$ March 2021; Available online $1^{\text {st }}$ April 2021 https://doi.org/10.31032/IJBPAS/2021/10.4.1033

\begin{abstract}
Lipases are very versatile enzymes that attract the attention of numerous industries. Different sources, including poultry, vegetables and microbiological sources, can derive lipase. The 2018 microbial lipase consumption demand estimated at USD 425.0 million is projected to reach USD 590.2 million by 2023 , up by $6.8 \%$ from 2018. Long chain triglyceride hydrolysis catalyses microbial lipases (EC 3.1.1.3). Logically, lipase enzyme microbial sources are complex and are also used for a wide range of industrial applications in the processing of modified molecules. The specific lipase (triacylglycerol acyl hydrolase) enzymes catalysed hydrolysis, esterification and alcoholytic reactions. Incorporating microbial lipases, immobilisation is best achieved and thus suited for many reactions and the aroma of the immobilisation processes needs to be boosted. The large-scale screening of lipase production includes Alcaligenes, Bacillus spp., Pseudomono spp., Achromobacter spp., Arthrobacter spp. of bacteria and Penicillium spp., Fusarium spp., Aspergillus spp., fungi. Lipases have provided a favourable view as a multifunctional biological catalyst to address the needs of a range of industries, including biodiesel, food and drinks, leather, textiles, pharmaceuticals and
\end{abstract}


medicines. This review provides an overview of microbial lipase sources as well as key aspects of microbial lipases production.

Keywords: Environment, Microorganism, Lipases, Enzyme

\section{INTRODUCTION}

Important $\mathrm{R} \& \mathrm{D}$ activities in the field of industrial enzymes are being conducted now, which both contribute to the manufacture and performance of a range of new products. Nearly 4000 enzymes are now known, of which approximately 200 are used commercially. According to a Business Communications Company, Inc. survey, the global demand for industrial enzymes was estimated at $\$ 2000$ million in 2004. Industrial enzyme volume growth rates range from $4 \%$ to $5 \%$ of the AAGR (an annual average growth rate). The result is price cuts due to an increase in the number of smaller industrial players.This will result in a demand growth of just over 3 percent over the next 4 years and an increase of approx. \$2352 million in 2009 to the overall industrial enzyme market. A minimum of 75 percent is hydrolytically active for all the industrial enzymes, including lipases. Lipases remain enzymatically active in organic solvents and are widely accepted as perfect instruments for organic chemists. A variety of studies were conducted to study activity in the different chemical, physical and environmental conditions of microbial enzymes [1, 2]. There have now been extensively examined advances made in the field of thermophile microbe enzymes in various scientific publications. The excellent work in molecular biology such as the 3D and biotech application of lipases from bacterium to fungi shows an enormous interest in lipases [3]. Enzymes are commonly used in specialised synthesis in the fields of scientific study, cosmetic processing, medical diagnosis and chemical analysis and in therapeutic applications. Lipases have special characteristics that interact with aqueous and non-aqueous media of these well-known major enzymes. Their ability to use a relatively large variety of substrates, which require no cofactors, high thermal stability, $\mathrm{pH}$ and organic solvents is the primary factor for this. The enantioselective and regioselective nature of lipases were used for the resolution of chiral products, fat alteration, coca butter constituent's synthesis, biofuels and a synthesis of personal care products and flavour enhancers (Jaeger and Reetz, 
1998). The chemical, regional and enantio-specific characteristics of these enzymes have therefore been of significant concern to scientists and industries [4].

\section{SOURCE OF LIPASE:}

Lipases may be obtained mainly from animals, tissues of calves or lambs, as well as hog and pig pancreatic tissues. Among other disadvantages of animal lipases are the presence of trypsin in pig-pancreatic lipases resulting in bitter degustation of amino acids, the presence of residual animal hormones or viruses and their adverse effects on vegetarian or Czech diets [5].

Plant lipases are also available but are not commercially exploited because of their output and processes. Thus, because of the technical and economic benefits microbial lipases currently receive greater attention when the organisms are grown in a medium containing the appropriate nutrients in controlled conditions. Furthermore, microorganism lipase production is subject to strains, growth medium composition, cultivation conditions, $\mathrm{pH}$, temperature and the type in sources of carbon and nitrogen [6]. In general, bacterial, fungal, yeast and actinomycotic sources of extracellular lipases are considered preferred and facilitate the recovery from cultivated bouillon of enzymes: although the major commercially viable strains are Candida,
Pseudomonas, Mucor, Rhizopus and Geotrichum Sp [7]. Microbial lipases are an important group of biotechnologically valuable enzymes, owing to the versatility of their applied properties and ease of mass production.

\section{LIPASE IMPLEMENTATION:}

Lipase Applications Lipases are an integral part of the food, leather industry and of various bioremediation processes in the dairy industry, pharmaceutical, agrochemical and detergents industries [8]. Lipases have realised their potential in modern industry due to their involvement in various industrial reactions, either in aqueous or organic systems, depending on their specificity. Due to their diverse enzymatic properties, microbial lipases find appealing applications in industry. For the production of lipases of desirable properties, newer microbes must be screened. Understanding the relationships in the structural function will enable researchers to tailor new biotechnology lipases [9].

\section{LIPASES IN THE FAT AND OLEOCHEMICAL INDUSTRIES:}

Lipases are a type of hydrolase that acts on carboxylic ester bonds. Lipases are enzymes that hydrolyse triglycerides into diglycerides, monoglycerides, fatty acids, and glycerol.Lipases have a wide range of applications in the oleochemical industry because they reduce thermal degradation during hydrolysis, glycolysis, and alcoholic 
reactions while also saving energy. Commercial use of C. cylindracea lipase in soap production has been reported [10]. Because of their structure, some fats are far more valuable than others. Less valuable fats can be converted into more useful species by combining chemical methods, but the results are often unpredictable. Lipase-catalysed transesterification of less expensive oils, for example, can be used to produce cocoa butter from palm midfraction [11]. Lipases have a wide range of applications in the oleochemical industry because they save energy and reduce thermal degradation during hydrolysis, glycerolises, and alcoholises [12].

DETERGENT INDUSTRIES LIPASES:

The enzyme industry has made great efforts to introduce lipases as the second detergent group after the large commercial success of proteases as detergent additives. Furthermore, in order to assess lipase compatibility, blanking agents for the removal of fat have been compared with several commercially used detergents. The use of detergent in washing machines is increasingly popular with washing detergent, which transfers softness to materials, anti-stativity, water-proofing. Different laundry brands claim that different laundry detergent qualities on the market are very common [13]. Thermomyces.sp. is the most commonly used detergent lipase [14]. The spp of
Pseudomonas. Other formulations like Lumafast and Lipomax contained therein [15]. The lipase elements cause detergents to increase and prevent them from scaling.

\section{LIPASE IN THE MANUFACTURE OF BIODEGRADABLE POLYMERS:}

Lipases have become important groups of enzymes in organic synthesis due to their wide range of applications. Lipases, as a biocatalyst, are useful in the synthesis of biodegradable compounds. Recently, it was reported that 1-Butyl locate was produced by direct esterification of butanol, and oleic acid tends to decrease the viscosity of biodiesel during the winter. For its application in organic syntheses, lipases have become one of the most important enzyme groups. In the production of useful biodegradable compounds, lipases may be used as biocatalysts. Like lubricants, trimethylolpropane esters were synthesised. In presence of organic solvent systems, lipases may also catalyse ester syntheses andtransesterification reactions. Therefore, bio-catalysed polyesters can be produced biodegradable. Lipase biocatalysts may contain aromatic polyesters [16].

MEDICAL AND PHARMACEUTICAL LIPASE APPLICATION:

Lipases are important in the transesterification and hydrolysis application of pharmaceutical products. In the production of specialty lipids and digestive aids they play a leading role [17]. The 
temperature alteration during the esterification reaction changes enantiomeric and stereo preference values dramatically. Lipases can be used as digestive aids. Lipases are Tumor Necrosis Factor activators and can thus be used in the treatment of malignant tumours. Despite the fact that Human Gastric Lipase (HGL) is the most stable acid lipase and a good candidate tool for enzyme substitution therapy.

Lipases were previously used to treat gastrointestinal disorders, dyspepsia, and cutaneous manifestations of digestive allergies. In the modification of monoglycerides for use in pharmaceutical applications, lipases are important [18].

LIPASE IN FOOD PROCESSING, AROMA DEVELOPMENT, AND PRODUCTIVITY IMPROVEMENT:

Lipase mediated changes based on regiospecific and fatty acid specific microbial lipases are of great value and can be exploited for the retaliation of vegetable oils, as modifications to the enzyme specific and can be carried out under moderate reaction conditions and inexpensive oils, will likely be prominent in the oil industry in the tailoring of structured lipids [19-20]. Lipases are now an essential component of the modern food industry. It is desired for the production of cheese flavours as well as the interesterification of fats and oils. It also hastens cheese ripening and lipolysis of butter, fats, and cream. The addition of lipases causes the release of short chain $(\mathrm{C} 4$ and C6) fatty acids, which gives the product a sharp, tangy flavour, while the release of medium chain fatty acids (C12 and $\mathrm{C} 14$ ) causes the product to have a soapy taste. Cocoa butter is a high-value fat with a melting point of $37^{\circ} \mathrm{C}$ that contains palmitic acid and stearic acid. In short chain acids and alcohols, the aspergillus lipases were highly selective while the propionic acid, butanol, pentanol and hexanol were selective in Candida rugosa lipase [20].

\section{COSMETIC AND PERFUMERY:}

Lipases have the potential which can be used in cosmetics and perfumery because they have activities in surfactants and aroma production. Esterification of glycerol's produces monoarylglycerol's and diacylglycerols, which are used as surfactants in the cosmetics and perfume industries. As a biocatalyst, immobilised Rhizomucor meihei lipase was used. The company claims that using the enzyme instead of the traditional acid catalyst results in much higher quality products that require minimal downstream refining [21]. The manufacturer states that the total cost of production is slightly higher than that of the old way, but that the cost is justified by an improved quality of the end product. Retinoids in cosmetics and pharmaceutical 
products such as skin care products have great commercial potential. Catalytic reaction of incapacitated lipase was prepared for water-soluble retinol derivative [21].

\section{LIPASES ARE BEING USED IN THE} TREATMENT OF WASTE, EFFLUENT, SEWAGE AND OIL BIODEGRADATION:

Lipases are used in activated sludge and other aerobic waste treatment systems, where thin layers of fats must be continually removed from the surface of aerated tanks to allow oxygen to pass through.Petroleum hydrocarbon biodegradation is a result of indigenous, cold-suited microorganisms that degrade these contaminants in freezing environment, including in alpine soils. Fungal species can be used to degrade oil spills as well as in the coastal environment and in enzymatic oil processing in industry [22]. Lipases are used in the active sludge process and in other aerobic waste processes, which are required to continuously remove thin layers of fats from the air tank site in order to permit the transfer of oxygen.

\section{CONCLUSION}

Lipase applications are increasingly expanding, and new applications in these sectors are still being explored. Despite the fact that lipases have a wide range of applications in the food, detergent, pharmaceutical, leather, cosmetic, and paper industries, their industrial applications are limited by their high production costs, small commercialization, and lack of performance of some lipasemediated processes. Lipases are an extremely polyvalent group of extracellular bacterial enzymes which can carry out various important reactions and thus offer a fascinating field for future research. New synthetic processes can be conducted in a large and continuous screening at low temperature for new microorganisms for their lipolytic enzymes. This can therefore pave the way to solve problems relating to biotechnology and the environment. Lipases are outstanding biocatalysts for use in various industries. Lipases can catalyse new reactions. The increasing demand for lipases has shifted the trend towards new lipases prospecting, improving the properties of existing lipases in established technical applications and creating new enzymes tailored to completely new application areas. As a result, modern genetic engineering techniques, combined with a growing understanding of structure and function, are allowing for further adaptation to industrial needs and the creation of novel applications.

\section{ACKNOWLEDGEMENT}

It's our privilege and honour to express our sincerest gratitude to the Parul University, Vadodara, Gujarat for providing me all the 
necessary support and facilities including state of the art infrastructural facilities with advanced technological scientific laboratories and everything else that was required to carry out this work.

\section{REFERENCES}

[1] Andualema, B., and A. Gessesse. "Microbial lipases and their industrial applications: review. Biotechnol 11: 100-118." (2012): 118.

[2] Sharma, D., B. Sharma, and A. K. Shukla. "Biotechnological approach of microbial lipase: a review. " Biotechnology 10.1 (2011): 23-40.

[3] Rubin, Byron. Lipases Part B: Enzyme characterization and utilization. Ed. Edward A. Dennis. San Diego: Academic Press, 1997.

[4] Saxena, R. K., et al. "Purification strategies for microbial lipases. "Journal of microbiological methods 52.1 (2003): 1-18.

[5] Vakhlu, Jyoti. "Yeast lipases: enzyme purification, biochemical properties and gene cloning. " Electronic Journal of Biotechnology 9.1 (2006): 0-0.

[6] Gupta, R., N. Gupta, and P. Rathi. "Bacterial lipases: an overview of production, purification and biochemical properties." Applied microbiology and biotechnology 64.6 (2004): 763781.

[7] Ertuğrul, Sevgi, Gönül Dönmez, and Serpil Takaç. "Isolation of lipase producing Bacillus sp. from olive mill wastewater and improving its enzyme activity. " Journal of Hazardous Materials 149.3 (2007): 720-724.

[8] Patil, Kishore J., Manojkumar Z. Chopda, and Raghunath $\mathrm{T}$. Mahajan. "Lipase biodiversity. "Indian Journal of Science and Technology 4.8 (2011): 971-982.

[9] Jaeger, K. E., B. W. Dijkstra, and M. T. Reetz. "Bacterial biocatalysts: molecular biology, threedimensional structures, and biotechnological applications of lipases." Annual Reviews in Microbiology 53.1 (1999): 315-351

[10] Saxena, R. K. "Microbial lipases: potential biocatalysts for the future industry." Curr. Sci. 77 (1999): 101-115.

[11] Hasan, Fariha, Aamer Ali Shah, and Abdul Hameed. "Industrial applications of microbial lipases. "Enzyme and Microbial technology 39.2 (2006): 235-251.

[12] Arbige, Michael V., and Wayne H. Pitcher. "Industrial enzymology: a look towards the future." Trends in 
Biotechnology 7.12 (1989): 330335.

[13] Verma, N., S. Thakur, and A. K. Bhatt. "Microbial lipases: industrial applications and properties (a review)." Int Res $J$ Biol Sci 1.8 (2012): 88-92.

[14] Gillis, A. "Research discovers new roles for lipases." Journal of the American Oil Chemists' Society 65.6 (1988): 846-852.

[15] Lenting, H. B. M., et al. "Identification of lipase for use in household.detergents." Internation al Meeting: Lipases Structure, Function and Protein Engineering (Book of Abstracts). Elsinore, Denmark. 1993.

[16] Linko, Yu-Yen, et al. "Biodegradable products by lipase biocatalysis." Journal of biotechnology 66.1 (1998): 41-50.

[17] Woolley, Paul. "Lipases; their structure, biochemistry and application." sequence analysis of lipases, esterases and related proteins (1994): 27-28.

[18] Sharma, Rohit, Yusuf Chisti, and Uttam Chand Banerjee. "Production, purification, characterization, and applications of lipases." Biotechnology advances 19.8, (2001): 627-662.
[19] Gupta, Rani, Pooja Rathi, and Sapna Bradoo. "Lipase mediated upgradation of dietary fats and oils." Critical reviews in food science and nutrition 3.6 (2003): 635-644.

[20] Hasan, Fariha, Aamer Ali Shah, and Abdul Hameed. "Industrial applications of microbial lipases. "Enzyme and Microbial technology 39.2 (2006): 235-251.

[21] Hasan, Fariha, Aamer Ali Shah, and Abdul Hameed. "Industrial applications of microbial lipases. "Enzyme and Microbial technology 39.2 (2006): 235-251.

[22] Gopinath, Subash CB, et al. "Strategies to characterize fungal lipases for applications in medicine and dairy industry. "BioMed Research International 2013 (2013). 